\title{
Public awareness and use of direct-to-consumer personal genomic tests from four state population-based surveys, and implications for clinical and public health practice
}

\author{
Katherine Kolor, $\mathrm{PhD}^{1}$, Debra Duquette, $\mathrm{MS}^{2}$, Amy Zlot, $\mathrm{MPH}^{3}$, Joan Foland, MHS, MPhil', Beth \\ Anderson, $\mathrm{MPH}^{2}$, Rebecca Giles, $\mathrm{MPH}^{5}$, Jennifer Wrathall, $\mathrm{MPH}^{5}$ and Muin J. Khoury, MD, PhD
}

Purpose: Direct-to-consumer personal genomic tests are widely available, but population-based data are limited on awareness and use of these tests among the general public in the United States.

Methods: We assessed awareness and use of direct-to-consumer personal genomic tests in Connecticut, Michigan, Oregon, and Utah using the 2009 Behavioral Risk Factor Surveillance System and compared the state results to the 2008 national HealthStyles survey results.

Results: Awareness was the highest in Oregon (29.1\%) and the lowest in Michigan (15.8\%). Factors associated with awareness across all states and nationally were higher education, higher income, and increasing age, except among those 75 years or older. Less than $1 \%$ of respondents had used the tests, with about one-half to three-quarters of those sharing the results with a health-care provider.
Conclusions: Awareness of direct-to-consumer genetic tests is greater in this study as compared with a related study conducted in 2006, whereas use is similarly low in both studies. The few respondents who reported using the tests often reported sharing their results with their health-care provider, indicating an important opportunity for health-care providers to offer patient education regarding these tests. Public health agencies have important roles in surveillance, education, and policy development on direct-to-consumer genomic tests.

\section{Genet Med 2012:14(10):860-867}

Key Words: awareness and use; direct-to-consumer; personal genomic tests; population-based; practice implications

\section{INTRODUCTION}

A number of private companies have been marketing and providing genetic tests to consumers that do not require the participation of a health-care provider. Direct-to-consumer (DTC) personal genomic tests, which examine up to 1 million or more genetic variants to inform disease risk and prevention strategies, were first introduced in 2007. Other DTC genetic tests, such as nutrigenomic tests, which are geared toward tailoring nutritional and physical activity interventions based on individuals' genetic makeup, have been available for many years. The legal landscape of DTC genetic testing varies in the United States by state. ${ }^{1}$ DTC personal genomic tests are currently offered for purchase to residents of 48 US states and the District of Columbia (ref 2 as one example), with New York and Maryland excepted; however, the specific test results provided may vary based on state law (ref 3 as one example). For some states, clinical laboratory tests on human samples, with certain exceptions for specific tests authorized by law, must be ordered by health-care providers and/or the results reported to health-care providers, restrictions that might effectively prohibit DTC personal genomic testing services; however, personal genomic tests are sometimes marketed for informational and educational purposes only, and the reach of testing restrictions is often limited to laboratories located within state. ${ }^{4,5}$

The validity, utility, and delivery models of DTC personal genomic tests, including evidentiary, ethical, and regulatory issues, have been examined by state and federal health agencies and in the scientific literature. ${ }^{6,7}$ Such issues relate to the scientific basis underlying health-related marketing claims, including the limited predictive value of the tests; quality standards and accreditation of testing laboratories; involvement of a suitably trained health-care provider in test provision; gaps in federal oversight of DTC genetic testing; and gaps in privacy and research protections. In 2009, a multidisciplinary workgroup examined the scientific foundation for DTC personal genomic tests and found that a rigorous research agenda is needed to assess the validity and utility of these tests and the balance of benefits and harms. ${ }^{8}$ In 2010, these tests were the subject of a congressional hearing ${ }^{9}$ and a highly critical report by the US Government Accountability Office, which found that test results were "misleading and of little or no practical use."10

Published data are limited on public awareness and use of DTC genetic tests, despite their widespread availability. ${ }^{11-14}$ In 2006, Goddard et al. ${ }^{14}$ examined awareness and use of DTC

\footnotetext{
${ }^{1}$ Office of Public Health Genomics, Centers for Disease Control and Prevention, Atlanta, Georgia, USA; ${ }^{2}$ Michigan Department of Community Health, Lansing, Michigan, USA; ${ }^{3}$ Oregon Genetics Program, Public Health Division, Oregon Health Authority, Portland, Oregon, USA; ${ }^{4}$ Genomics Office, Connecticut Department of Public Health, Hartford, Connecticut, USA; ${ }^{5}$ Utah Department of Health, Salt Lake City, Utah, USA. Correspondence: Katherine Kolor (kkolor@cdc.gov)
} 
nutrigenomic tests in three state population-based surveys and nationally, using similar questions and methodology as our study, and found that awareness varied across states (15.9$29.1 \%)$ and use was very low $(<1 \%)$. To explore the public health impact of these tests, and to obtain more recent population-based estimates of awareness and use of DTC genetic tests in this rapidly evolving field, we developed and administered questions using the 2009 Behavioral Risk Factor Surveillance Systems (BRFSS) in Connecticut, Michigan, Oregon, and Utah to assess the awareness of the public and use of DTC personal genomic tests.

\section{MATERIALS AND METHODS}

Four questions were added to the 2009 BRFSS in Connecticut, Michigan, Oregon, and Utah. The BRFSS collects information about health conditions, risk behaviors, and health-care access and utilization in the United States using a random-digit-dialed telephone survey of the noninstitutionalized population aged 18 years or older from each state. Residential landline phone numbers were used. Oregon, Connecticut, and Utah offered the survey in both English and Spanish. Response rates were 44.2\% for Connecticut, $56.9 \%$ for Michigan, $42.1 \%$ for Oregon, and $66.6 \%$ for Utah. ${ }^{15}$ State results were compared to national results from the 2008 HealthStyles survey conducted by Synovate, for which a more limited analysis was previously reported. ${ }^{12}$

The main outcome variables included in our analysis were awareness of DTC personal genomic tests and use of such tests. These were assessed by asking the following questions: "Several companies are advertising genetic tests that examine a person's entire genetic makeup for health risks. You can order these tests directly, without the involvement of a healthcare provider. Have you heard or read anything about these tests?" and "Have you ever had one of these tests?" If respondents answered yes to the latter, they were asked, "Did you discuss the results with your health care provider?" There were subtle differences in question phrasing across states (Table 1).

Study covariates included the following sociodemographic variables: age group, sex, race/ethnicity, household income category, education level, and health insurance coverage. Other covariates included the following health-related behaviors or characteristics: general health status, daily consumption of fruits and vegetables, level of physical activity (CDC Recommendations met (30+ min of moderate physical activity five or more days per week, or vigorous physical activity for $20+$ min three or more days per week) vs. not met), smoking status (current vs. former/never smoked regularly), self-reported body mass index category (underweight $/$ normal $\left(<25.0 \mathrm{~kg} / \mathrm{m}^{2}\right)$ vs. overweight/obese $\left(25.0 \mathrm{~kg} / \mathrm{m}^{2}\right.$ or higher $)$ ), and alcohol consumption (binge drinking ( 5 or more drinks on any occasion for men and 4 or more drinks on any occasion for women) vs. no binge drinking).

Respondents were also asked about their sources of information for DTC personal genomic tests, based on a list of sources that was provided (Figure 1a,b). This question varied by state. Connecticut and Michigan asked, "From which sources did you first hear or read anything about these tests?" Oregon, Utah, and the national HealthStyles survey allowed multiple responses by asking, "Where did you hear or read about these tests?"

Data from each state were analyzed separately with Stata version 11.2 (StataCorp LP, College Station, TX) (Oregon); SASCallable SUDAAN, Release 10.0.1 (Research Triangle Institute, Research Triangle Park, NC) (Michigan); or SAS, Release 9.2 (SAS Institute, Cary, NC) (Utah, Connecticut, and HealthStyles data). Sample data were weighted to reflect the demographic characteristics of the adult population in each of the states or nationally. Sample sizes (number of survey respondents) were reported as unweighted numbers.

$\chi^{2}$ tests were used to compare differences in awareness by population characteristics and selected behaviors. Multivariate logistic regression was performed to identify factors that remained significant $(P<0.05)$ after adjusting for other confounders. Statistical analyses were not adjusted for multiple comparisons.

The human research protection offices at the Centers for Disease Control and Prevention, Connecticut Department of Public Health, Michigan Department of Health, Oregon Department of Human Services, and Utah Department of Health have determined that the BRFSS survey and the HealthStyles survey are exempt from institutional review.

\section{RESULTS}

Awareness of DTC personal genomic tests ranged from 15.8\% in Michigan to $29.1 \%$ in Oregon (Table 1). In each of the states and nationally, less than $1 \%$ of the population reported ever using a DTC personal genomic test (Table 1). The source most commonly cited for where respondents had read or heard of DTC genomic tests in all four states and nationally was "TV or radio," with "newspaper" and "magazine" ranked either second or third (depending on the state), and "Internet" fourth. The least commonly cited sources were "health professional," "friend," and "family member." (Figure 1a,b). Of those reporting using a DTC personal genomic test, approximately one-half to three-quarters reported sharing the results with their healthcare provider, although these results are based on small sample sizes (data not shown).

Bivariate analyses showed that race, age, income, and education were significantly associated with awareness in all states and nationally (Table 2). Covariates that remained in the bivariate and logistic regression analyses included age, sex, race/ethnicity, household income, education, insurance status, self-reported health status, physical activity, and fruits and vegetables consumption. Additional lifestyle variables, such as smoking status, obesity, and alcohol consumption were found not to be significantly associated with respondents' awareness of DTC personal genomic tests and were excluded from further analysis.

After controlling for covariates in logistic regression models, ages 50-74 years, higher education, and income levels of $\$ 75,000$ or more remained significantly associated with awareness of DTC personal genomic tests for all of the states and 
Table 1 Questions ${ }^{\mathrm{a}}$ and results of State Behavioral Risk Factor Surveillance System (2009) and National HealthStyles (2008) surveys on awareness and use of direct-to-consumer personal genomic tests

Questions $^{\mathrm{a}}$

Awareness or use $\%$ yes $(95 \% \mathrm{Cl})$

Connecticut $(n=6,019)$

Several companies [specific company names provided in the question] are advertising genetic tests that examine a person's entire genetic makeup for health risks. You can order these tests directly, without the involvement of a healthcare provider, by swabbing the inside of your cheek and sending that sample to the company. Have you heard or read anything about these tests?

Have you ever had one of these tests?

Michigan $(n=5,883)$

Several companies [specific company names provided in the question] are advertising genetic tests that examine a person's entire genetic makeup for health risks. You can order these tests directly, without the involvement of a healthcare provider, by swabbing the inside of your cheek and sending that sample to the company. Have you heard or read anything about these tests?

Have you ever had one of these tests?

$0.5(0.3-0.8)$

Oregon $(n=1,931)$

Several companies [specific company names provided in the question] are advertising genetic tests that scan a person's entire genetic makeup for health risks. You can order these tests directly, without the involvement of a healthcare provider. Have you heard or read about these tests?

$29.1(26.4-31.9)$

Have you ever used any of these tests?

Utah $(n=2,606)$

Several companies [specific company names provided in the question] are advertising genetic tests that scan a person's entire genetic makeup for health risks. You can order these tests directly, without the involvement of a healthcare provider. Have you heard or read about these tests?

$27.5(25.1-29.8)$

Have you ever had one of these tests?

$0.6(0.2-0.9)$

National $(n=5,399)$

Genetic tests that scan a person's entire genetic makeup for potential health risks are currently being marketed directly to consumers by several different companies [specific company names provided in the question]. Have you heard or read about these genetic tests?

Have you ever had a genetic test that scanned your entire genetic makeup for potential health risks from a direct-to-consumer company [specific company names provided in the question]?

Bold text indicates differences in survey question phrasing among the four states.

$\mathrm{Cl}$, confidence interval; DTC, direct-to-consumer.

aRespondents aware of DTC genomic tests were also asked about the source of information about the tests, and respondents who reported having the tests were asked whether they shared the test results with a health-care provider (questions not shown). bNational results were previously reported as unweighted analyses (ref. 12), but are presented here weighted to adjust observations to a nationally representative distribution.

nationally (Table 3). Nationally and in Utah, non-Hispanic whites were significantly more likely than Hispanics to be aware of DTC genetic testing; nationally and in Michigan, nonHispanic whites were significantly more likely to be aware than non-Hispanic blacks. In Connecticut, Michigan, and Utah, eating five or more servings of fruits and vegetables daily was a predictor of awareness of testing (Table 3).

\section{DISCUSSION}

Our analyses provide the first multistate population-based information on adult awareness and use of DTC personal genomic tests. The number of combined respondents surveyed across states was 16,439 adults, which is more than three times the number of respondents included in other published studies on DTC personal genomic tests. ${ }^{12,16-21}$ Furthermore, because previous published studies are not representative of the population at large, ${ }^{22}$ these data representative of four states are invaluable in assessing awareness and use of such tests among
US adults. In addition, a strength of our methodology is that it allows comparisons between data for four states and national data. Although there were differences in awareness of DTC personal genomics tests, there were striking similarities among the states and nationally with $0.2-0.8 \%$ of adults reporting the use of DTC personal genomic tests.

We estimate that $\sim 200,000$ to over 1 million adults in the United States had used DTC personal genomic tests as of the administration of surveys in 2008 and 2009. Although we were not able to directly determine the absolute number of adults using DTC personal genomic tests as of 2009, a recent publication that evaluated website traffic reports from the three largest DTC personal genomic test companies estimated that 20,000 30,000 people purchased such a test in $2009 .{ }^{23}$ The estimates by Wright and Gregory-Jones ${ }^{23}$ were based on unsubstantiated assumptions that less than $5 \%$ of website visitors purchased a DTC personal genomic test. Their estimates are consistent with a March 2010 article in the popular media that reported that 

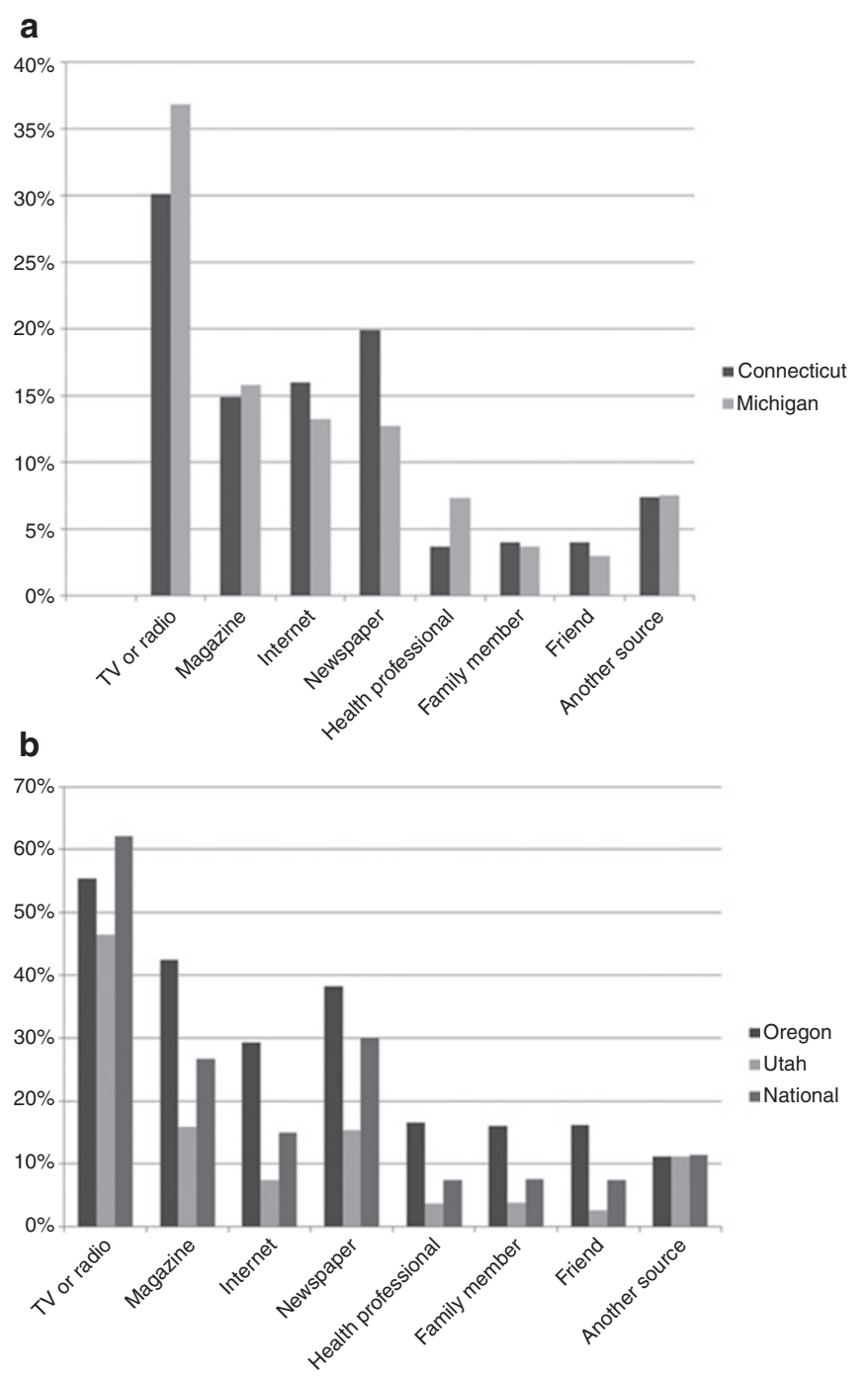

Figure 1 Sources most commonly cited of where respondents had read or heard of DTC personal genomic tests. (a) From which sources did you first hear or read anything about these tests? (b) Where did you hear or read about these tests? DTC, direct-to-consumer.

each of the three companies mentioned by name as examples in the current surveys had at most 35,000 customers, although the source of this information was not identified. ${ }^{24}$ Because information regarding the number and demographics of DTC personal genomics test customers is proprietary and not available to the public through DTC companies, ${ }^{5}$ our approach to using existing state and national consumer surveys to obtain such estimates helps to address these data gaps.

Three of the four participating states (i.e., Michigan, Oregon, and Utah) had also examined awareness and use of DTC nutrigenomic tests in 2006. ${ }^{14}$ In comparison to this previous population-based study of DTC nutrigenomic tests, awareness of DTC genetic tests is greater in 2009 (15.9-29.1\%) than in 2006 (7.6-24.4\%), with Michigan consistently having the lowest and Oregon having the highest awareness rates. However, the estimates of usage of DTC genetic tests in these states and nationally in the two studies are similar at less than $1 \%$.
A likely reason for the greater awareness is the significant media attention that DTC personal genomic tests received in this 3-year time period, culminating with "Time" magazine naming the "Retail DNA test" as the 2008 "Invention of the Year."23,25 The influence of the media appears to be supported by our findings that among respondents aware of DTC personal genomic tests that media outlets (i.e., television, radio, newspapers, and magazines) were the most likely source of where respondents had read or heard about such tests. Other studies have also found that the mass media are the primary source of DTC genetic information. ${ }^{26,27}$ However, this media involvement may have unexpected negative consequences and may be related in part to our finding of a low uptake of DTC personal genomic tests. On the basis of 10 focus groups conducted by Rahm et al., ${ }^{26}$ many participants expressed negative thoughts about DTC genetic testing, primarily focused on the media as the messenger and questioning the scientific validity and utility of such tests. Rahm et al. ${ }^{26}$ also concluded that although the media may influence the perceived importance of an issue, consumers further interpret media messages based on their own risk perceptions and social groups.

The demographic profiles of respondents more likely to be aware of DTC personal genomic tests in 2009 and DTC nutrigenomic tests in 2006 remained similar across states and nationally. Respondents who were older (except those 75 years or older), more affluent, and more highly educated were significantly more aware of such tests. Similar to our findings, Langford et al. ${ }^{13}$ found that awareness of DTC genetic tests was greatest among 50-74 year olds, in contrast to other studies, which have suggested that younger age is significantly related to awareness ${ }^{21}$ or that there is no association related to age. ${ }^{11}$ Similar to our findings, Bloss et al. ${ }^{17}$ suggested that younger people are more likely to be unsure about DTC personal genetic testing. In contrast to our 2009 findings, the 2006 survey found that race and ethnicity were not consistently associated with awareness of DTC nutrigenomic tests. Our findings are also similar to those of Hensley et al. ${ }^{28}$ who found that African Americans were less likely to access a DTC multiplex genetic test. Our 2009 findings are also similar to a recent report by Langford et al. ${ }^{13}$ that examined 6,754 respondents and found that black respondents were less aware of DTC genetic tests as compared with white respondents. Langford et al. ${ }^{13}$ further reported that this finding may be partially related to numeracy skills. ${ }^{13}$ Furthermore, Lachance et al. ${ }^{29}$ reported that the average reading level of DTC personal genetic testing websites was grade 15 , which is significantly above the average reading skill of adults in the United States. The recognition of differences in awareness of DTC personal genomic tests among different segments of our population is important in order to address potential literacy and numeracy needs, and to ensure that all consumers regardless of race, ethnicity, age, education, and income can be fully informed when making decisions about health and personal genetic testing.

Although the demographics of adults aware of DTC personal genomic tests are similar between states and nationally, 
Table 2 Sociodemographic and lifestyle characteristics of respondents by awareness of DTC personal genomic tests

\begin{tabular}{|c|c|c|c|c|c|c|c|c|c|c|}
\hline \multirow[b]{2}{*}{ Characteristic } & \multicolumn{2}{|c|}{ Connecticut } & \multicolumn{2}{|c|}{ Michigan } & \multicolumn{2}{|c|}{ Oregon } & \multicolumn{2}{|c|}{ Utah } & \multicolumn{2}{|c|}{ Nationala } \\
\hline & $\%$ Yes & $P^{\mathrm{b}}$ & $\%$ Yes & $P^{b}$ & $\%$ Yes & $P^{b}$ & $\%$ Yes & $P^{b}$ & $\%$ Yes & $P^{b}$ \\
\hline Total awareness of DTC tests & 22.9 & & 15.8 & & 29.1 & & 27.5 & & 22.1 & \\
\hline Male & 22.6 & & 14.9 & & 29.9 & & 27.6 & & 20.2 & \\
\hline Female & 23.3 & & 16.6 & & 28.3 & & 27.4 & & 23.8 & \\
\hline White non-Hispanic & 24.3 & & 17.3 & & 31.0 & & 28.7 & & 23.6 & \\
\hline Black non-Hispanic & 12.7 & & 9.3 & & $N A^{c}$ & & $N A^{c}$ & & 18.0 & \\
\hline Hispanic & 10.7 & & 11.8 & & $N A^{c}$ & & 11.0 & & 16.5 & \\
\hline Other $^{d}$ & 24.0 & & 11.2 & & 18.4 & & 28.5 & & 24.5 & \\
\hline $75+$ & 17.1 & & 11.7 & & 32.7 & & 31.8 & & 17.2 & \\
\hline Household income & & $<0.0001$ & & $<0.0001$ & & $<0.0001$ & & $<0.0001$ & & $<0.0001$ \\
\hline$<\$ 25 K$ & 17.9 & & 9.0 & & 21.3 & & 19.4 & & 15.2 & \\
\hline$\$ 25 K-\$ 49.9 K$ & 18.7 & & 14.9 & & 25.5 & & 26.3 & & 21.3 & \\
\hline$\$ 50 \mathrm{~K}-\$ 74.9 \mathrm{~K}$ & 19.9 & & 19.9 & & 30.0 & & 26.5 & & 21.8 & \\
\hline$\$ 75 K+$ & 28.2 & & 21.2 & & 41.2 & & 36.7 & & 28.4 & \\
\hline Education level & & $<0.0001$ & & $<0.0001$ & & $<0.0001$ & & $<0.0001$ & & $<0.0001$ \\
\hline High school or less & 14.8 & & 9.0 & & 20.1 & & 18.2 & & 13.7 & \\
\hline At least some college & 21.4 & & 15.4 & & 28.6 & & 25.2 & & 22.2 & \\
\hline Health insurance ${ }^{e}$ & & 0.2502 & & $<0.0001$ & & 0.0010 & & 0.0043 & & \\
\hline Yes & 23.3 & & 16.9 & & 31.3 & & 29.4 & & $N A^{f}$ & \\
\hline No & 19.2 & & 8.3 & & 16.8 & & 17.2 & & $N A^{f}$ & \\
\hline Physical activity ${ }^{9}$ & & 0.0058 & & 0.0001 & & 0.0779 & & 0.27 & & \\
\hline Recommendations met & 23.7 & & 18.7 & & 31.2 & & 28.9 & & $N A^{f}$ & \\
\hline Recommendations not met & 14.6 & & 13.5 & & 26.3 & & 26.2 & & $N A^{f}$ & \\
\hline Fruit and vegetable consumption & & $<0.0001$ & & 0.0001 & & 0.0516 & & 0.0021 & & \\
\hline$\geq 5$ servings per day & 29.0 & & 20.8 & & 33.9 & & 34.0 & & $N A^{f}$ & \\
\hline$<5$ servings per day & 20.5 & & 14.3 & & 27.4 & & 25.4 & & $N A^{f}$ & \\
\hline
\end{tabular}

DTC, direct-to-consumer.

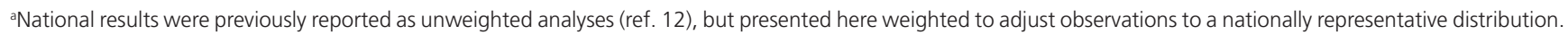
${ }^{b}$ Reported $P$ values are not adjusted for multiple comparisons. 'Data unavailable due to small sample size. ${ }^{\text {DThe }}$ "other" category includes: American Indian/Alaska Native, Asian, Native Hawaiian/other Pacific Islander, and other races. ${ }^{e}$ Any kind of health care insurance, including government plans. ${ }^{f}$ Corresponding questions not included in the HealthStyles survey. ${ }^{930+}$ min of moderate physical activity five or more days per week, or vigorous physical activity for $20+$ min three or more days per week.

the percentage of adults aware of DTC personal genomics tests varies between states. The reasons for the differences in awareness between states are not known. Also, in contrast to our findings, a smaller study of Puerto Rican residents found that an astounding $56 \%$ of respondents were aware of DTC genetic tests and $4 \%$ of respondents had used such tests. ${ }^{11}$ The Puerto Rican study also found lower awareness among men and smokers and no association with awareness for age and education. ${ }^{11}$ 
Table 3 Predictors of awareness of DTC personal genomic tests

\begin{tabular}{|c|c|c|c|c|c|}
\hline Characteristic & $\begin{array}{c}\text { Connecticut } \\
\text { AOR }(95 \% \mathrm{Cl})^{\mathrm{a}}\end{array}$ & $\begin{array}{c}\text { Michigan } \\
\text { AOR }(95 \% \mathrm{Cl})^{\mathrm{b}}\end{array}$ & $\begin{array}{c}\text { Oregon } \\
\text { AOR }(95 \% \mathrm{Cl})^{\mathrm{a}}\end{array}$ & $\begin{array}{c}\text { Utah } \\
\text { AOR }(95 \% \mathrm{Cl})^{\mathrm{b}}\end{array}$ & $\begin{array}{c}\text { National } \\
\text { AOR }(95 \% \mathrm{Cl})\end{array}$ \\
\hline \multicolumn{6}{|l|}{ Sex } \\
\hline Female vs. male & $1.0(0.8-1.2)$ & $1.1(0.9-1.4)$ & $0.9(0.7-1.2)$ & $1.0(0.8-1.3)$ & $1.4(1.2-1.6)$ \\
\hline \multicolumn{6}{|l|}{ Race and ethnicity } \\
\hline Black non-Hispanic vs. white non-Hispanic & $0.7(0.4-1.1)$ & $0.6(0.4-0.9)$ & $N A^{d}$ & $N A^{d}$ & $0.7(0.6-0.9)$ \\
\hline Hispanic vs. white Non-Hispanic & $0.6(0.3-1.1)$ & $0.9(0.5-1.8)$ & $N A^{d}$ & $0.5(0.2-1.0)^{\dagger}$ & $0.8(0.6-0.9)$ \\
\hline \multicolumn{6}{|l|}{ Age, years } \\
\hline $50-74$ vs. $18-49$ & $1.6(1.3-2.0)$ & $1.8(1.4-2.2)$ & $1.9(1.3-2.8)$ & $2.3(1.8-2.9)$ & $1.7(1.5-1.9)$ \\
\hline $75+$ vs. $18-49$ & $1.0(0.7-1.3)$ & $1.3(0.9-1.8)$ & $2.9(2.0-4.1)$ & $1.9(1.3-2.8)$ & $0.9(0.7-1.3)$ \\
\hline \multicolumn{6}{|l|}{ Household income } \\
\hline \multicolumn{6}{|l|}{ Education level } \\
\hline At least some college vs. high school or less & $1.5(1.0-2.1)$ & $1.6(1.2-2.1)$ & $1.3(0.9-2.0)$ & $1.4(1.0-2.1)$ & $1.7(1.4-2.1)$ \\
\hline College graduate vs. high school or less & $1.9(1.4-2.6)$ & $2.5(1.8-3.3)$ & $1.8(1.1-2.7)$ & $2.2(1.5-3.2)$ & $2.4(1.9-2.9)$ \\
\hline \multicolumn{6}{|l|}{ Health status } \\
\hline Good vs. fair/poor & $1.3(0.9-1.8)$ & $0.9(0.6-1.3)$ & $1.0(0.7-1.4)$ & $0.9(0.6-1.4)$ & $0.8(0.7-1.0)^{\star *}$ \\
\hline Excellent/very good vs. fair/poor & $1.7(1.2-2.4)$ & $1.1(0.8-1.6)$ & $0.9(0.6-1.5)$ & $1.1(0.7-1.7)$ & $0.9(0.8-1.1)$ \\
\hline \multicolumn{6}{|l|}{ Health insurance ${ }^{f}$} \\
\hline Yes vs. no & $0.9(0.5-1.5)$ & $1.2(0.8-2.0)$ & $1.2(0.7-2.1)$ & $1.3(0.7-2.6)$ & $\mathrm{NA}^{9}$ \\
\hline \multicolumn{6}{|l|}{ Physical activity ${ }^{h}$} \\
\hline
\end{tabular}

AOR, adjusted odds ratio; $95 \% \mathrm{Cl}, 95 \%$ confidence interval; DTC, direct-to-consumer; NA, not available.

aLogistic regression models controlled for age, income, education, and fruit and vegetable consumption. 'bogistic regression models controlled for race/ethnicity, age, income, education, and fruit and vegetable consumption. 'Logistic regression models controlled for sex, race/ethnicity, age, income, education, and health status.

¿Data unavailable due to small sample size. ${ }^{e}$ The "other" category includes: American Indian/Alaska Native, Asian, Native Hawaiian/Other Pacific Islander, and other races. ${ }^{\dagger}$ Any kind of health care insurance, including government plans. ${ }^{9}$ Corresponding questions not included in the HealthStyles survey. ${ }^{\mathrm{h}} 30+$ min of moderate physical activity five or more days per week, or vigorous physical activity for $20+$ min three or more days per week.

${ }^{*} P=0.039 ;{ }^{*} P=0.019 ; * * * P=0.031{ }^{\dagger} P=0.040 ;{ }^{\ddagger} P=0.042$.

The variations in awareness between states may be related to the marketing strategies of these companies; however, there is no published evidence available that demonstrates variations in marketing of these tests by geographic areas of the United States. Another possible explanation for these differences is that health literacy and numeracy skills may differ between states, with higher numeracy skills being associated with awareness as reported by Langford et al..$^{13}$; however, we have not been able to locate published comparison of numeracy skills by state populations and therefore are not able to further explore this possibility. In 2007, the Genetics \& Public Policy Center published a comparison of state laws for DTC testing obtained through surveys of state government officials. ${ }^{1}$ Although the results of this survey have not been reproduced by others, 13 states reported having laws that prohibited DTC genetic testing (including Michigan and Connecticut), 12 permitted DTC testing for specified categories of tests (including Oregon), and the other states had no known laws restricting DTC genetic testing (including Utah). ${ }^{1}$ In our study, Michigan was found to have the lowest rates of awareness of DTC personal genomic tests, which may be related to the more stringent interpretation of Michigan's state laws.

It is especially noteworthy that the use of DTC nutrigenomic tests in 2006 and the use of DTC personal genomic tests in 2009 remained consistently low at less than $1 \%$. The specific reason for this consistent finding is not known; however, possible reasons for low utilization of such tests include the inability for consumers to pay the cost of DTC personal genomic tests, general lack of consumer interest regarding such tests ${ }^{30}$ consumer mistrust in purchasing online genomic services, ${ }^{17,18,31,32}$ cautionary 
messages and findings about using DTC personal genomics tests from states and federal agencies, ${ }^{8-10}$ legislation restricting DTC genetic test use in some states, ${ }^{1,5}$ and position statements about potential harms regarding DTC personal genomic testing from professional organizations. ${ }^{33}$ When the cost of a DTC personal genomic test is reduced or eliminated, the use of DTC personal genomic tests in select populations is higher (15-30\%) as compared with our findings. ${ }^{16,34}$ Therefore, it seems that the cost of testing may be an important barrier to utilization. Based on several published studies, ${ }^{17,18,31,32}$ consumers report having concerns regarding DTC genetic testing especially related to privacy, worry about receiving the results, and reliability of test results. On the basis of a recent worldwide systematic review of position statements, policies, and recommendations regarding DTC genetic testing, ${ }^{33}$ existing positions and policies describe more potential harms than benefits of DTC genetic tests, with some policies calling for prohibition of such tests.

A recent systematic review of the literature ${ }^{22}$ found that the majority of consumers desire guidance by a health professional when considering DTC personal genetic tests. In fact, although studies have found that $78-92 \%$ of the general public state that they would share their DTC genetic test results with a physician if they were tested, ${ }^{20,32,35}$ previous studies have found that $\sim 28 \%$ of DTC genetic testing customers actually have shared their results with a health-care provider, typically their primary-care provider. ${ }^{17,19}$ As compared with these previous studies, our study found that about one-half or more respondents who had used a DTC personal genomic test had shared their results with a health-care provider. Kaufman et al. ${ }^{19}$ suggest that sharing DTC risk reports with health-care professionals may add considerable value to the test result and facilitate appropriate health-related decisions. It is encouraging that several DTC companies have recently changed their delivery model and now require consumers to order their tests via a physician. ${ }^{36}$

There has been a surge of DTC personal genomic test offerings, which has been described as a "premature deployment of genomic technologies without a scientific evidence base.", ${ }^{\prime, 12}$ Our findings indicate significant sociodemographic and lifestyle disparities in awareness of DTC genomic tests, suggesting an unmet need to increase consumer awareness of genomics, especially in disparate populations. The promise of genomics to improve personal and population health will be achieved only if and when genomic services and technologies are evidence based and accessible to all individuals, regardless of race/ethnicity, income, and education. ${ }^{37}$

Limitations of our study include subtle differences in survey question wording, differences in the sociodemographic composition of the survey populations, and differences in survey methodology. A limitation of the 2009 state BRFSS was that respondents of the four states needed access to a working landline telephone at their residence. Another limitation of our study is that the health literacy and numeracy of our survey populations were not evaluated. Last, our data are based on selfreported information that was not able to be confirmed through other sources and that may be inaccurate if respondents did not understand the survey questions.

\section{ACKNOWLEDGEMENTS}

This work was supported in part by the Centers for Disease Control and Prevention through cooperative agreements awarded to the Michigan Department of Community Health (5U38GD000054), the Oregon Department of Human Services (1U38GD000061), and the Connecticut Department of Public Health (3U58/DP00200601W1). The authors appreciate the assistance and support of Chris Fussman, Jennifer McLosky, John Gehring, Kerry Silvey, Robert Nystrom, Nanette Newell, and Katherine Bradley. The findings and conclusions in this report are those of the authors and do not necessarily represent the views of the funding agencies.

\section{DISCLOSURE}

The authors declare no conflicts of interest.

\section{REFERENCES}

1. Genomics and Public Policy Center. Survey of Direct-to-Consumer Testing Statutes and Regulations. 2007. http://www.dnapolicy.org/resources/ DTCStateLawChart.pdf. Accessed 21 March 2012

2. 23andme. Shipping. https://www.23andme.com/store/shipping/. Accessed 21 March 2012.

3. deCODEme. Service Agreement. https://www.decodeme.com/serviceagreement. Accessed 2 April 2012

4. McGuire A, Burke W. An unwelcome side effect of direct-to-consumer personal genome testing: Raiding the medical commons. JAMA 2008;300:2669-2671.

5. Hogarth S, Javitt G, Melzer D. The current landscape for direct-to-consumer genetic testing: legal, ethical, and policy issues. Annu Rev Genomics Hum Genet 2008;9:161-182.

6. Caulfield T, McGuire AL. Direct-to-consumer genetic testing: perceptions, problems, and policy responses. Annu Rev Med 2012;63:23-33.

7. Spencer DH, Lockwood C, Topol E, et al. Direct-to-consumer genetic testing: reliable or risky? Clin Chem 2011;57:1641-1644.

8. Khoury MJ, McBride CM, Schully SD, et al.; Centers for Disease Control and Prevention. The Scientific Foundation for personal genomics: recommendations from a National Institutes of Health-Centers for Disease Control and Prevention multidisciplinary workshop. Genet Med 2009;11:559-567.

9. U.S. House of Representatives Committee on Energy and Commerce. Hearing on "Direct-To-Consumer Genetic Testing and the Consequences to the Public Health." 2010. http://democrats.energycommerce.house. gov/index.php? $q=$ hearing/hearing-on-direct-to-consumer-genetictesting-and-the-consequences-to-the-public-health. Accessed 8 September 2011.

10. U.S. Government Accountability Office. Direct-To-Consumer Genetic Tests: Misleading Test Results Are Further Complicated by Deceptive Marketing and Other Questionable Practices. 2010. http://www.gao.gov/new.items/ d10847t.pdf. Accessed 8 September 2011.

11. Ortiz AP, López M, Flores LT, et al. Awareness of direct-to-consumer genetic tests and use of genetic tests among Puerto Rican adults, 2009. Prev Chronic Dis 2011;8:A110.

12. Kolor K, Liu T, St Pierre J, Khoury MJ. Health care provider and consumer awareness, perceptions, and use of direct-to-consumer personal genomic tests, United States, 2008. Genet Med 2009;11:595.

13. Langford AT, Resnicow K, Roberts JS, Zikmund-Fisher BJ. "Racial and Ethnic Differences in Direct-to-Consumer Genetic Tests Awareness in HINTS 2007: Sociodemographic and Numeracy Correlates". J Genet Couns 2012;21: 440-447.

14. Goddard KA, Duquette D, Zlot A, et al. Public awareness and use of directto-consumer genetic tests: results from 3 state population-based surveys, 2006. Am J Public Health 2009:99:442-445.

15. Centers for Disease Control and Prevention. 2009 BRFSS Summary Data Quality Report, Version \#1, Table 11: BRFSS outcome rates by state. 2011. 
ftp://ftp.cdc.gov/pub/Data/Brfss/2009_Summary_Data_Quality_Report.pdf. Accessed 17 May 2011.

16. McBride CM, Alford SH, Reid RJ, Larson EB, Baxevanis AD, Brody LC. Characteristics of users of online personalized genomic risk assessments: implications for physician-patient interactions. Genet Med 2009;11: 582-587.

17. Bloss CS, Ornowski L, Silver E, et al. Consumer perceptions of directto-consumer personalized genomic risk assessments. Genet Med 2010;12:556-566.

18. McGuire AL, Diaz CM, Wang T, Hilsenbeck SG. Social networkers' attitudes toward direct-to-consumer personal genome testing. Am J Bioeth 2009;9:3-10.

19. Kaufman DJ, Bollinger JM, Dvoskin RL, Scott JA. Risky Business: Risk Perception and the Use of Medical Services among Customers of DTC Personal Genetic Testing. J Genet Couns 2012;21:413-422.

20. Leighton JW, Valverde K, Bernhardt BA. The general public's understanding and perception of direct-to-consumer genetic test results. Public Health Genomics 2012;15:11-21.

21. Cherkas LF, Harris JM, Levinson E, Spector TD, Prainsack B. A survey of UK public interest in internet-based personal genome testing. PLOS ONE 2010;5:e13473.

22. Goldsmith L, Jackson L, O'Connor A, Skirton H. Direct-to-consumer genomic testing: systematic review of the literature on user perspectives. Eur J Hum Genet; e-pub ahead of print February 2012.

23. Wright CF, Gregory-Jones S. Size of the direct-to-consumer genomic testing market. Genet Med 2010;12:594.

24. Pollack A. Consumers slow to embrace the age of genomics. NY Times (Print). 2010. http://www.nytimes.com/2010/03/20/business/20consumergene. html?_r=2\&fta=y. Accessed 2 April 2012.

25. Sweeny K, Legg AM. Predictors of interest in direct-to-consumer genetic testing. Psychol Health 2011;26:1259-1272.

26. Rahm AK, Feigelson HS, Wagner N, et al. Perception of Direct-To-Consumer Genetic Testing and Direct-To-Consumer Advertising of Genetic Tests among Members of a Large Managed Care Organization. J Genet Couns 2012;21:448-461
27. Liu Y, Pearson YE. Direct to consumer marketing of predictive medical genetic tests: assessment of current practices and policy recommendations. J Publ Pol Market 2008;27:131-148.

28. Hensley Alford S, McBride CM, Reid RJ, Larson EB, Baxevanis AD, Brody LC. Participation in genetic testing research varies by social group. Public Health Genomics 2011;14:85-93.

29. Lachance CR, Erby LA, Ford BM, Allen VC Jr, Kaphingst KA. Informational content, literacy demands, and usability of websites offering healthrelated genetic tests directly to consumers. Genet Med 2010;12: 304-312.

30. Burrill \& Company. Personalized Medicine and Wellness Survey: Executive Summary. http://www.burrillandco.com/content/CWSurvey_61708.pdf. Accessed 1 April 2012.

31. Wilde A, Meiser B, Mitchell PB, Hadzi-Pavlovic D, Schofield PR. Community interest in predictive genetic testing for susceptibility to major depressive disorder in a large national sample. Psychol Med 2011;41:1605-1613.

32. Gollust SE, Gordon ES, Zayac C, et al. Motivations and perceptions of early adopters of personalized genomics: perspectives from research participants. Public Health Genomics 2012;15:22-30.

33. Skirton H, Goldsmith L, Jackson L, O'Connor A. Direct to consumer genetic testing: a systematic review of position statements, policies and recommendations. Clin Genet; e-pub ahead of print February 2012.

34. Haga SB, Carrig MM, O'Daniel JM, et al. Genomic risk profiling: attitudes and use in personal and clinical care of primary care physicians who offer risk profiling. J Gen Intern Med 2011;26:834-840.

35. McGuire AL, Evans BJ, Caulfield T, Burke W. Science and regulation. Regulating direct-to-consumer personal genome testing. Science 2010;330:181-182.

36. Su Y, Howard HC, Borry P. Users' motivations to purchase direct-toconsumer genome-wide testing: an exploratory study of personal stories. J Community Genet 2011;2:135-146.

37. Khoury MJ, Bowen MS, Burke W, et al. Current priorities for public health practice in addressing the role of human genomics in improving population health. Am J Prev Med 2011;40:486-493. 